\title{
Prediction of groundwater suitability for irrigation using artificial neural network model: a case study of Nanded tehsil, Maharashtra, India
}

\author{
Vasant Madhav Wagh ${ }^{1} \cdot$ Dipak Baburao Panaskar ${ }^{1} \cdot$ Aniket Avinash Muley $^{2} \cdot$ \\ Shrikant Vitthal Mukate ${ }^{1} \cdot$ Yogesh Popatrao Lolage $^{1} \cdot$ Manesh Laxman Aamalawar $^{1}$
}

Received: 22 October 2016/Accepted: 31 October 2016/Published online: 10 November 2016

(C) Springer International Publishing Switzerland 2016

\begin{abstract}
This study presents an artificial neural network (ANN) model predicting values of sodium adsorption ratio (SAR), residual sodium carbonate, magnesium adsorption ratio, Kellys ratio and percent sodium $(\% \mathrm{Na})$ in the groundwater of Nanded tehsil. The 50 groundwater samples were analyzed for different physicochemical parameters such as $\mathrm{pH}, \mathrm{EC}, \mathrm{TDS}, \mathrm{Ca}, \mathrm{Mg}, \mathrm{Na}, \mathrm{K}, \mathrm{Cl}, \mathrm{CO}_{3}, \mathrm{HCO}_{3}$, $\mathrm{SO}_{4}$ and $\mathrm{NO}_{3}$, for the pre monsoon season 2012. The ANN model is developed through $\mathrm{R}$ programming and compared with MS-Excel software. These parameters were used as input variables in the ANN based groundwater quality indices for irrigation suitability prediction. The best back propagation algorithm and neuron numbers were determined for optimization of the model architecture. The resilient backpropagation algorithm with weight back
\end{abstract}

Aniket Avinash Muley

aniket.muley@gmail.com

Vasant Madhav Wagh

Wagh.vasant@gmail.com

Dipak Baburao Panaskar

dbpanaskar@rediffmail.com

Shrikant Vitthal Mukate

mukateshrikant@gmail.com

Yogesh Popatrao Lolage

lolage.yogesh@gmail.com

Manesh Laxman Aamalawar

a.manesh23@gmail.com

1 School of Earth Sciences, Swami Ramanand Teerth Marathwada University, Nanded, Maharashtra, India

2 School of Mathematical Sciences, Swami Ramanand Teerth Marathwada University, Nanded, Maharashtra, India tracking was used for optimization of seven neurons through sensitive analysis. It showed that a network with seven neurons was highly accurate in predicting the irrigation suitability indices. The relative mean squared error, coefficient of determination $\left(\mathrm{R}^{2}\right)$ and mean absolute relative error between experimental data and model outputs were calculated. It is observed that is a good agreement between actual data and ANN outputs of groundwater for irrigation suitability indices for training and testing datasets. The spatial distribution maps of measured and predicted values of irrigation indices were prepared using ArcGIS software. Hence, the result confirms that the ANN model is an applied tool to predict the groundwater suitability for irrigation purpose in Nanded tehsil.

Keywords Neural network - Backpropagation algorithm · Irrigation suitability $\cdot$ Nanded tehsil

\section{Introduction}

Groundwater is an important natural resource for human survival system and one of the major sources of irrigation. The crop productivity and soil quality also depends on water used for irrigation. The poor quality water used for irrigation may reduce the crop yield and also affects soil quality (Ayers and Westcot 1994). In India, groundwater meets the $65 \%$ irrigation and $85 \%$ of drinking demand. However, surface water share has declined in irrigation from $60 \%$ in 1950 to $30 \%$ in the first decade of the twentyfirst century (CGWB 2010). The groundwater quality is deteriorating day by day due to overexploitation of groundwater, surplus use of chemical fertilizers and pesticides which percolate into aquifer in many parts of the country (Goyal et al. 2010; Jangam et al. 2015). 


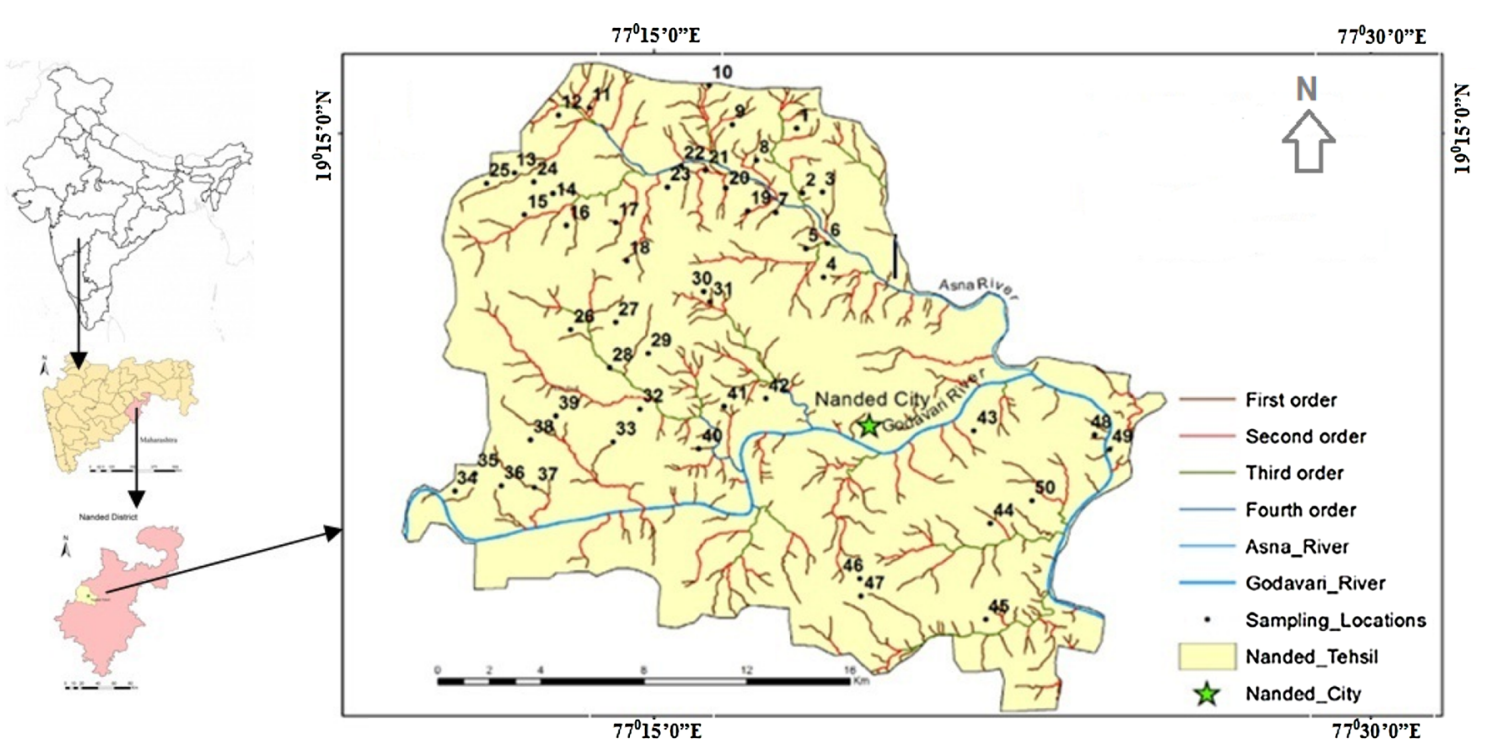

Fig. 1 Study area with sample locations

The suitability of groundwater for irrigation is considerably based on the concentration of cations and anions present in the ground water. The sodium adsorption ratio (SAR), residual sodium carbonate (RSC), magnesium adsorption ratio (MAR), Kellys ratio (KR) and \% Na plays a vital role to determine the suitability of groundwater for irrigation purpose (Richards 1954; Raghunath 1987; Kelley 1963; Doneen 1964). The investigation of water suitability for irrigation should focus on salt concentration, which increases soil salinity and affects soil fertility and crop productivity (Kirda 1997).

The artificial neural network is a system of processing elements called neurons, which are connected to each other by a set of weights. It takes number of inputs weight them, sums them up, adds a bias and uses a results as the argument for singular valued function, the transfer function, which results in the neurons output (Strik et al. 2005). In the ANN model three layers are used first one is input variables, then hidden neurons and the output. The input variables are processed with some weight and the predicted output is delivered. Neural networks have flexible nonlinear function mapping capability that can approximate any continuous measurable function with arbitrarily desired accuracy, whereas most of the commonly used empirical models do not have this property. Second, being nonparametric and data-driven, neural networks impose few prior assumptions on the underlying process from which data are generated. Also, high computation rate, learning ability through pattern presentation, prediction of unknown patterns, and flexibility affronts for noisy patterns are other advantages of using ANNs.
The aim of the present study is to develop the optimized ANN model to determine the groundwater suitability for irrigation. The physicochemical analysis is carried out to measure the value of SAR, RSC, MAR, KR and $\% \mathrm{Na}$. The ANN resilient backpropagation algorithm is adopted to predict the values of the same. The different thematic maps prepared to identify the spatial variation among the measured and predicted values of these ratios. This study will be helpful to identify the irrigation water suitability particularly in arid and semi arid environment within short period of time.

\section{Study area}

The present study area is located in the Nanded District of Maharashtra, which lies between latitudes $19^{\circ} 03^{\prime}: 19^{\circ} 17^{\prime} \mathrm{N}$ and longitudes $77^{\circ} 10^{\prime}: 77^{\circ} 25^{\prime} \mathrm{E}$ with total geographical area of $447.27 \mathrm{~km}^{2}$ (Fig. 1). The Nanded tehsil receives an average rainfall of $767-1285 \mathrm{~mm}$, out of which $89 \%$ rainfall is received during $\mathrm{SW}$ monsoon. The temperature ranges from 13 to $42{ }^{\circ} \mathrm{C}$ in the study area (CGWB 2013). The Godavari is the major River flowing in SW to SE direction in the study area. The area is irrigated by the Godavari and Asna River and also irrigated by the left bank canal from Siddheshwar dam of the Purna project in the Parbhani district. Geologically, the Nanded tehsil is part of South East part of Deccan Volcanic Province of Cretaceous-Eocene age (Krishnan 1982). The black cotton soil and loamy to sandy soil are the dominant soil types. 
Table 1 Methodology/formulas adopted to analyze physicochemical parameters and Irrigation water suitability indices

\begin{tabular}{|c|c|}
\hline Parameter & Methodology/formula adopted \\
\hline $\mathrm{pH}$ & Multi-parameter PCS tester 35 \\
\hline \multicolumn{2}{|l|}{ EC } \\
\hline TDS & $\Sigma$ cations and anions \\
\hline $\mathrm{Ca}$ & Titration method (APHA 2005) \\
\hline \multicolumn{2}{|l|}{$\mathrm{Mg}$} \\
\hline \multicolumn{2}{|l|}{$\mathrm{CO}_{3}$} \\
\hline \multicolumn{2}{|l|}{$\mathrm{HCO}_{3}$} \\
\hline \multicolumn{2}{|l|}{$\mathrm{Cl}$} \\
\hline \multicolumn{2}{|l|}{ TH } \\
\hline $\mathrm{Na}$ & Flame photometer (Elico CL 361) \\
\hline \multicolumn{2}{|l|}{$\mathrm{K}$} \\
\hline $\mathrm{SO}_{4}$ & UV spectrophotometer (Shimadzu UV-1800) \\
\hline \multicolumn{2}{|l|}{$\mathrm{NO}_{3}$} \\
\hline SAR & $\mathrm{Na}^{+} /\left(\sqrt{\mathrm{Ca}^{2+}+\mathrm{Mg}^{2+} / 2}\right)$ \\
\hline RSC & $\left(\mathrm{CO}_{3}+\mathrm{HCO}_{3}\right)-(\mathrm{Ca}+\mathrm{Mg})$ \\
\hline $\mathrm{KR}$ & $\mathrm{Na}^{+} / \mathrm{Ca}^{2+}+\mathrm{Mg}^{2}$ \\
\hline MAR & $\mathrm{Mg} /(\mathrm{Ca}+\mathrm{Mg}) * 100$ \\
\hline$\% \mathrm{Na}$ & {$\left[\left(\mathrm{Na}^{+}+\mathrm{K}^{+}\right) /\left(\mathrm{Ca}^{2+}+\mathrm{Mg}^{2+}+\mathrm{Na}^{+}+\mathrm{K}^{+}\right)\right]^{*} 100$} \\
\hline
\end{tabular}

\section{Materials and methods}

Fifty representative groundwater samples were collected from different locations in rural and agricultural areas of Nanded tehsil during pre-monsoon season of 2012. A global positioning system (GPS) device used to record the location coordinates. The methodology adopted to calculate different physicochemical parameters and irrigation water suitability ratios are given in the Table 1 . The ions were converted from milligram per liter $(\mathrm{mg} / \mathrm{L})$ to mill equivalents per liter (meq/L) to measure the different irrigation suitability ratios. The DOS based STIFF software used to compute the ionic balance errors $( \pm 10 \%)$. The $\mathrm{R}$ and MS-Excel software were employed for computing descriptive statistics and ANN analysis of the data. Finally, we will turn to an examination of the recommended model with the designed neural network to predict the ground water suitability based on analytical results. The spatial distribution maps of measured and predicted values are demonstrated for the better understanding by ArcGIS 10.2 software.

\section{Selection of ANN model}

Multilayer perceptron (MLP) with back propagation (BP) algorithm has been adopted in designing different structures of the neural network (Sreekanth et al. 2009). In the multilayer neural network, depending on the pattern of relation between the materials, input is put in first layer and the output in the last layer by means of neurons weights, bias and the activity algorithm in the middle layer(s). In each structure, the input information, after processing, is put through to the next layer(s) through the output of the first layer neurons and finally, provided that it is acceptable, to the network output. The explicit expression for an output value of a three layered MLP is given by (Nourani et al. 2013) Eq. (1).

$y_{k}=f \circ\left[\sum_{i=1}^{M_{N}} W_{k j} \cdot f_{h}\left(\sum_{i=1}^{N_{N}} W_{j i} X_{i}+W_{j 0}\right)+W_{k 0}\right]$,

where, $W_{j i}$ is a weight in the hidden layer connecting the $i$ th neuron in the input layer and the $j$ th neuron in the hidden layer, $W_{j 0}$ is the bias for the $j$ th hidden neuron, $f_{h}$ is the activation function of the hidden neuron, $W_{k j}$ is a weight in the output layer connecting the $j$ th neuron in the hidden layer and the $k$ th neuron in the output layer, $W_{k 0}$ is the bias for the $k$ th output neuron, $f_{o}$ is the activation function for the output neuron, $X_{i}$ is $i$ th input variable for input layer and $y_{j}$ is computed output variable, $N_{N}$ and $M_{N}$ are the number of the neurons in the input and hidden layers.

The weights are different in the hidden and output layers, and their values can be changed during the network training process. Every neuron in each layer is connected to a neuron of an adjacent layer having different weights. Each neuron receives signals from the neurons of the previous layer weighted by the weighted connections between neurons except in the input layer. Neurons then produce an output signal by passing the summed signal through an activation function (Maqsood et al. 2005; Ghavidel and Montaseri 2014). The gradient descent, conjugate gradient, Levenberg-Marquardt, and etc. Learning algorithms can be used for training the MLP model (Kisi et al. 2015).

Normalized information was used as the network input, in which the software normalizes information. In this study, several training algorithms and functions performed using neuralnet and nnet tool of R software were adapted. Normalization of data ensures fast processing and convergence during training and minimizes prediction error (Rojas 1996). The input and output data (raw data) were normalized before subjecting to training and testing by transforming the data to the range of $0-1$ using the Eq. (2):

$\hat{X}=\frac{X-X_{\min }}{X_{\max }-X_{\min }}$.

When the neural networks training completed, the value of the networks output is normalized and it needs de- 
normalization transforming into the actual value. The equation is defined as follows (Eq. 3):

$X=\hat{X} \times\left(X_{\max }-X_{\min }\right)+X_{\min }$,

where, $X$ is original value, $X_{\min }$ and $X_{\max }$ are minimum and maximum values in the series, $\hat{X}$ is the normalized data.

The training/testing data split can have a significant impact on the results of the model. The cross-validation technique (Chang et al. 2013; Fijani et al. 2013) is used to divide the data sets. Based on this approach, 50 data points were divided in two sets; training $70 \%$ (35 samples) and testing 30\% (15 samples).

The neuralnet function is used in R programming for the development of ANN model. A vector is specified by number of hidden layers and hidden neurons in each layer. The resilient backpropagation algorithm with weight back tracking was used through sensitive analysis for 1-30 hidden neurons. Through the sensitivity analysis it is found that the seven neurons show the optimum $\mathrm{R}^{2}$, relative mean squared error (RMSE) and mean absolute relative error (MARE) for all the indices. So, further investigation the vector $(13,7,5)$ induces a neural network with specified number of neurons is used. The resilient back propagation with weight backtracking algorithm with cross entropy differentiable error function is considered and logistic function is used as an activation function with the assumption that logically output is not linear.

\section{Act criteria}

The adequacy of the ANN is evaluated by considering the $\mathrm{R}^{2}$ defined on the basis SAR, RSC, MAR, KR and $\% \mathrm{Na}$ estimation errors, also the values RMSE and MARE are used as the index to check the knack of model. The acceptance criterion rests on the quantitative error passing into the calculations and observations, including maximum $\mathrm{R}^{2}$, minimum RMSE and MARE value of error, being less than 1 and the relative error is computed.

The act of the simulation of training and testing sets was evaluated by following measures of goodness of fit: $\mathrm{R}^{2}$, RMSE and MARE shown in Eqs. 4, 5 and 6, respectively. The $R^{2}$ express the degree of the relation when two variables are linearly related. If $R^{2}$ is close to 1 , there is good correlation between the dependent and independent variables.

$R^{2}=\left[\sum_{i=1}^{N}\left(P_{i}-\bar{P}\right)\left(O_{i}-\bar{O}\right)\right]^{2}\left[\sum_{i=1}^{N}\left(P_{i}-\bar{P}\right)^{2}\left(O_{i}-\bar{O}\right)^{2}\right]^{-1}$,

$R M S E=\left[N^{-1} \sum_{i=1}^{N}\left(P_{i}-O_{i}\right)^{2}\right]^{0.5}$

$M A R E=\frac{1}{N} \sum_{i=1}^{N} \frac{\left|O_{i}-P_{i}\right|}{O_{i}} \times 100$,

where, $N$ is the number of observations, $P_{i}$ is the predicted values, $O_{i}$ is the observed data, $\bar{P}$ and $\bar{O}$ are the mean values for $P_{i}$ and $O_{i}$, respectively.

\section{Results and Discussion}

The Descriptive statistics of physicochemical parameters are computed and represented in Table 2.

Table 2 Descriptive statistics of the physicochemical parameters

\begin{tabular}{|c|c|c|c|c|c|c|c|c|}
\hline Variable & Mean & Minimum & Maximum & Standard deviation & Standard error & Kurtosis & Skewness & Range \\
\hline $\mathrm{pH}$ & 7.48 & 7.10 & 7.80 & 0.17 & 0.02 & -0.74 & -0.08 & 0.70 \\
\hline EC & 4889.58 & 843.00 & $64,963.00$ & $13,201.70$ & 1867.00 & 14.80 & 3.97 & $64,120.0$ \\
\hline $\mathrm{Ca}$ & 44.70 & 11.17 & 101.20 & 20.96 & 2.96 & 1.10 & 0.99 & 90.03 \\
\hline $\mathrm{Mg}$ & 32.34 & 9.10 & 61.51 & 11.83 & 1.67 & -0.01 & 0.08 & 52.41 \\
\hline $\mathrm{Na}$ & 110.68 & 29.10 & 315.90 & 71.90 & 10.17 & 0.56 & 1.09 & 286.80 \\
\hline $\mathrm{K}$ & 2.72 & 1.37 & 3.90 & 0.63 & 0.09 & -0.58 & -0.09 & 2.53 \\
\hline $\mathrm{CO}_{3}$ & 17.80 & 0.00 & 60.00 & 12.50 & 1.77 & 1.54 & 0.89 & 60.00 \\
\hline $\mathrm{HCO}_{3}$ & 186.60 & 80.00 & 470.00 & 77.92 & 11.02 & 5.03 & 1.96 & 390.00 \\
\hline $\mathrm{Cl}$ & 169.49 & 59.70 & 495.10 & 81.66 & 11.55 & 5.17 & 1.96 & 435.40 \\
\hline $\mathrm{NO}_{3}$ & 3.36 & 0.11 & 7.11 & 1.72 & 0.24 & -0.73 & -0.15 & 7.00 \\
\hline $\mathrm{SO}_{4}$ & 13.00 & 3.13 & 37.06 & 7.56 & 1.07 & 0.50 & 0.83 & 33.93 \\
\hline TDS & 580.69 & 337.74 & 1208.28 & 186.58 & 26.39 & 3.04 & 1.68 & 870.54 \\
\hline $\mathrm{TH}$ & 244.63 & 98.53 & 425.09 & 71.66 & 10.13 & 0.07 & 0.00 & 326.56 \\
\hline
\end{tabular}

All values expressed in $\mathrm{mg} / \mathrm{L}$ except $\mathrm{pH}$ and $\mathrm{EC}$ 


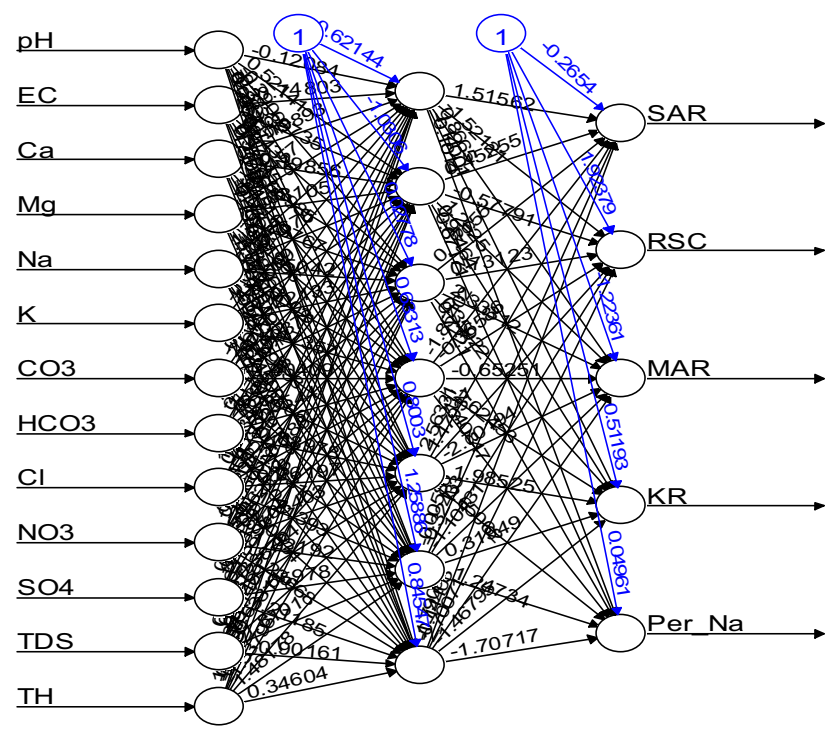

Fig. 2 Optimized ANN model

These all parameters are used as input layers with 7 hidden neurons to evaluate the groundwater suitability for the irrigation purpose.

The ANN plot shows the value of the function, in terms of training the iteration number (Fig. 2).

The applicability of ANN was investigated to predict the groundwater suitability for irrigation. The 50 observation wells in Nanded tehsil are studied. In ANN predicting model the selection of input variables is significant step, as it affects the model performance. In this context, selected all the physicochemical parameters such as $\mathrm{pH}, \mathrm{EC}$, TDS, $\mathrm{Ca}, \mathrm{Mg}, \mathrm{Na}, \mathrm{K}, \mathrm{Cl}, \mathrm{CO}_{3}, \mathrm{HCO}_{3}, \mathrm{SO}_{4}$ and $\mathrm{NO}_{3}$ were used as input variables for the prediction of different indices which represents the suitability of groundwater for irrigation purpose.

The accuracy of MLP is employed and the results of the ANN model are summarized in Table 3. The RMSE, $\mathrm{R}^{2}$ and MARE values of the predicted SAR model in training step were $0.17,0.997$ and $13.14 \%$, respectively.

Table 3 Accuracy of developed ANN model for the prediction of different irrigation water suitability indices in training steps

\begin{tabular}{lllc}
\hline Output result & $\mathrm{R}^{2}$ & RMSE & MARE (\%) \\
\hline SAR & 0.997 & 0.17 & 13.14 \\
RSC & 0.997 & 0.15 & 9.501 \\
MAR & 0.997 & 0.19 & 14.66 \\
KR & 0.997 & 0.2 & 13.58 \\
$\% \mathrm{Na}$ & 0.997 & 0.11 & 9.626 \\
\hline
\end{tabular}

The RMSE, $\mathrm{R}^{2}$ and MARE values of the predicted RSC model in training step were $0.15,0.997$ and $9.50 \%$, respectively. The RMSE, $\mathrm{R}^{2}$ and MARE values of the predicted MAR model in training step were 0.19, 0.997 and $14.66 \%$, respectively. The RMSE, $\mathrm{R}^{2}$ and MARE values of the predicted $\mathrm{KR}$ model in training step were $0.2,0.997$ and $13.58 \%$, respectively. The RMSE, $\mathrm{R}^{2}$ and MARE values of the predicted $\% \mathrm{Na}$ model in training step were $0.11,0.997$ and $9.62 \%$, respectively.

The Table 3 confirms that the MLP performance is in general, accurate and reliable. The high accuracy of the developed model is due to the high coefficient of determination. The sensitivity of different neurons in predicting the neural network of the model was carried out. It is observed that the seven neurons showing the less error for prediction of the groundwater irrigation suitability indices.

Figure 3a-e represents the different plots through MSExcel of measured and predicted indices of different groundwater irrigation suitability. It can be seen that, from these figures for the testing phase model is closer to exact fit line. The results of the model computed through MS-Excel are given in Table 4. The RMSE, $\mathrm{R}^{2}$ and MARE values of the predicted SAR model in training step were $0.22,0.97$ and $30.34 \%$, respectively. The RMSE, $\mathrm{R}^{2}$ and MARE values of the predicted RSC model in training step were $0.00,1.00$ and $0.28 \%$, respectively. The RMSE, $\mathrm{R}^{2}$ and MARE values of the predicted MAR model in training step were 21.81, 0.96 and 5.38\%, respectively. The RMSE, $\mathrm{R}^{2}$ and MARE values of the predicted KR model in training step were $0.16,0.95$ and $36.31 \%$, respectively. The RMSE, $\mathrm{R}^{2}$ and MARE values of the predicted $\% \mathrm{Na}$ model in training step were 10.34 , 0.99 and $5.84 \%$, respectively. The association between SAR, RSC, MAR, KR and $\% \mathrm{Na}$ ratios measured and observed values in the form of linearity and coefficient of determination indicates the reliability of the evaluated model.

\section{Spatial distribution of indices}

SAR is an important ratio to determine the water suitability for irrigation. It measures the sodium concentration over calcium and magnesium content in water. The excess sodium is hazardous to the crop due to its cementing effect which affects soil permeability and structure. From Table 5 it is confirmed that the predicted and measured values are nearly similar. The values are below ten and hence suitable for irrigation (Richards 1954). The spatial distribution map (Fig. 4a) of predicted 

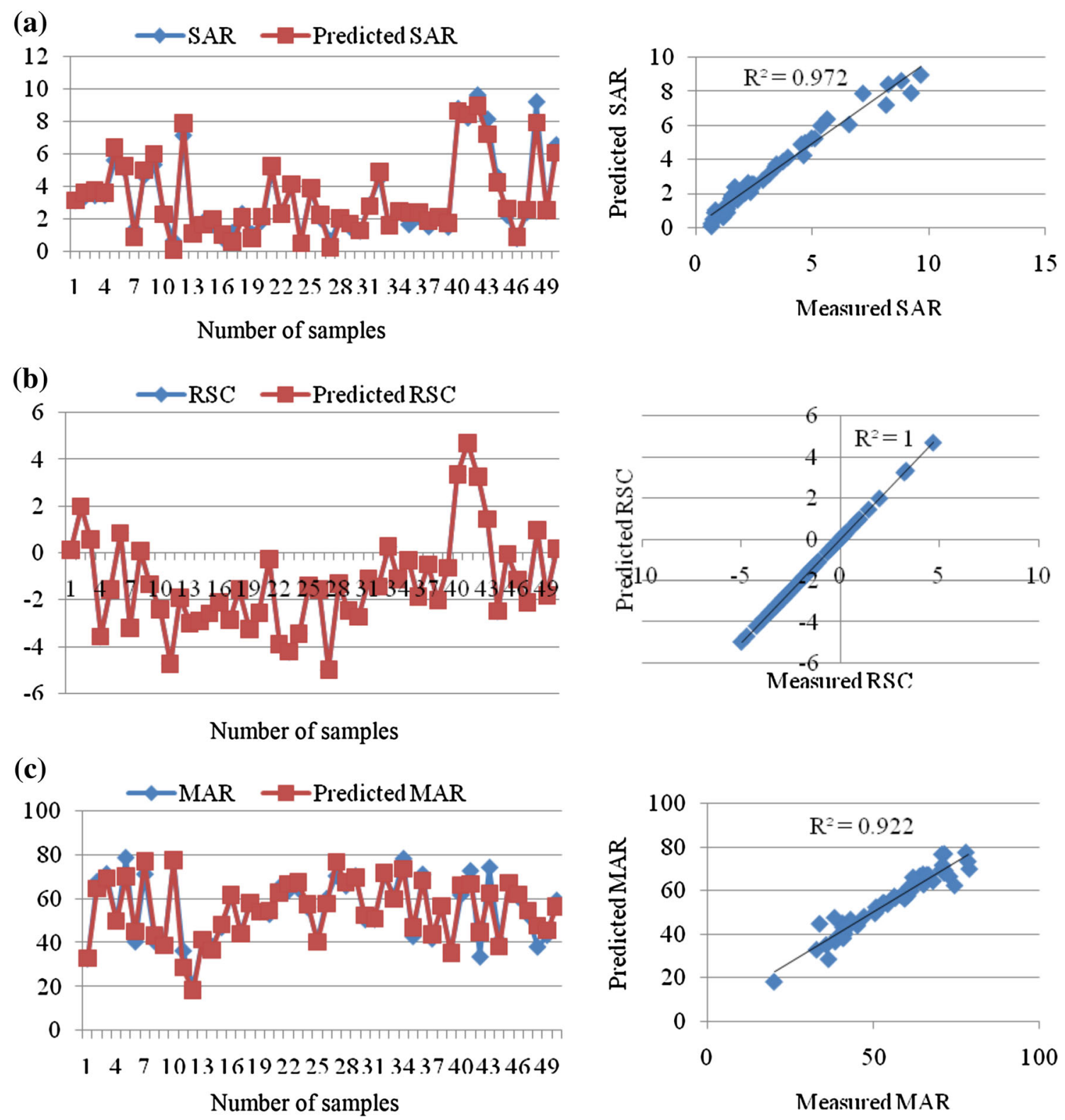

Fig. 3 Measured and Predicted values of a SAR, b RSC, c MAR, d KR and e \% Na

and measured values of SAR represents the similar distribution. The soil permeability is assessed by the concentration of carbonate and bicarbonate over calcium and magnesium ions by RSC ratio. The carbonate and bicarbonate ion precipitates the calcium and magnesium. Positive RSC value indicates that sodium built is possible which affects soil permeability (Eaton 1950). The ANN model is best fitted for RSC as it predicts the exact value as shown in Table 5 and spatial distribution map (Fig. 4b).

The present ANN model is best fit for \% sodium and MAR ratio. It is observed that predicted and measured 


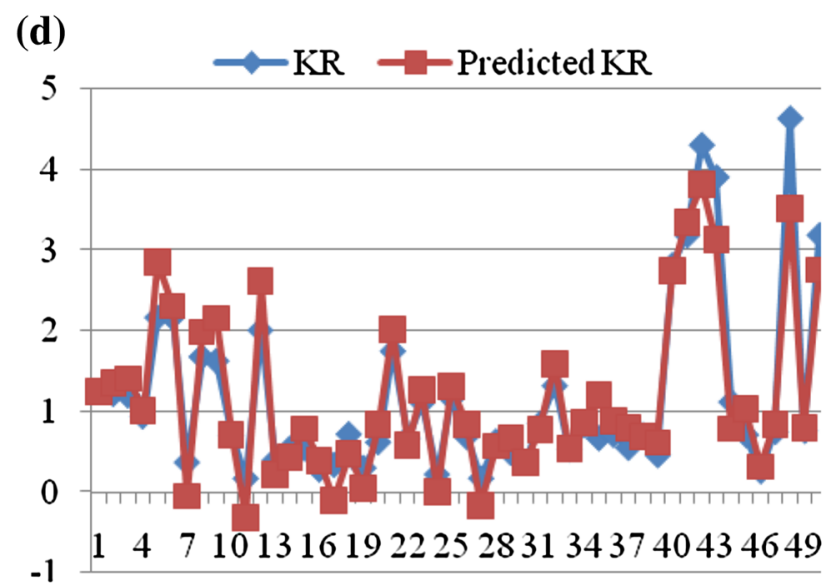

Number of samples

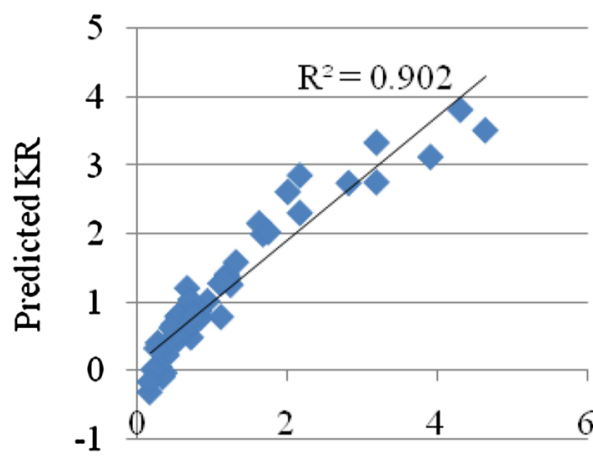

Measured KR

(e)
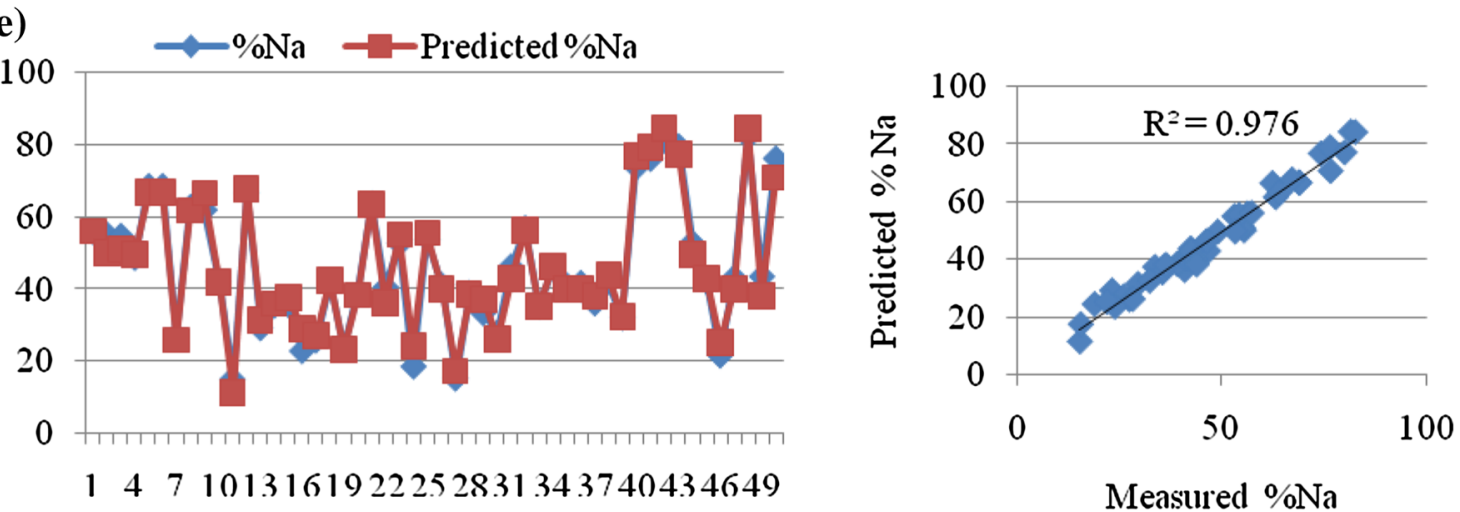

Number of samples

Fig. 3 continued

Table 4 Evaluation results of prediction different ratios (using MSExcel)

\begin{tabular}{llcc}
\hline Output ratio & $\mathrm{R}^{2}$ & RMSE & MARE $(\%)$ \\
\hline SAR & 0.97 & 0.22 & 30.34 \\
RSC & 1.00 & 0.00 & 0.28 \\
MAR & 0.92 & 21.81 & 5.38 \\
KR & 0.90 & 0.16 & 36.31 \\
$\% \mathrm{Na}$ & 0.98 & 10.34 & 5.84 \\
\hline
\end{tabular}

values of $\%$ sodium and MAR are almost same. The spatial distribution of these two indices is quite similar as represented in Fig. 4c and e, respectively.

Kelly ratio is used to measure sodium contents against calcium and magnesium. The high contents of sodium can cause undesirable effects on soil properties. From Table 5 it is confirms that measured and predicted average $\mathrm{KR}$ values are similar but there is a variation in spatial distribution and it is clearly observed in Fig. 4d.
Table 5 Descriptive statistics of measured and predicted values of irrigation water suitability indices

\begin{tabular}{|c|c|c|c|c|c|c|c|c|c|c|}
\hline \multirow[t]{2}{*}{ Parameter } & \multicolumn{5}{|c|}{ Measured } & \multicolumn{5}{|c|}{ Predicted } \\
\hline & SAR & RSC & $\mathrm{KR}$ & MAR & $\% \mathrm{Na}$ & SAR & RSC & KR & MAR & $\% \mathrm{Na}$ \\
\hline Min & 0.67 & -4.97 & 0.17 & 20.09 & 15.07 & 0.07 & -4.97 & -0.32 & 18.10 & 11.36 \\
\hline Max & 9.64 & 4.70 & 4.64 & 78.76 & 82.36 & 8.99 & 4.70 & 3.81 & 77.71 & 84.54 \\
\hline Average & 3.30 & -1.28 & 1.18 & 55.00 & 46.42 & 3.30 & -1.28 & 1.18 & 55.00 & 46.42 \\
\hline SD & 2.43 & 2.02 & 1.08 & 14.35 & 18.00 & 2.39 & 2.02 & 1.03 & 13.78 & 17.79 \\
\hline
\end{tabular}


(a)

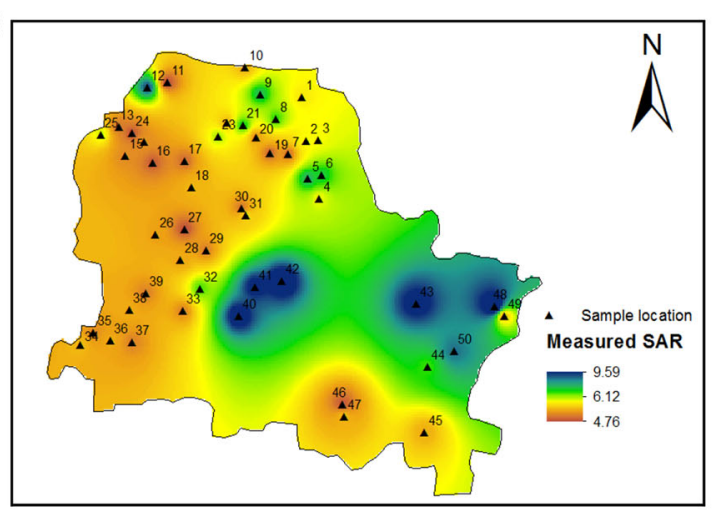

(b)

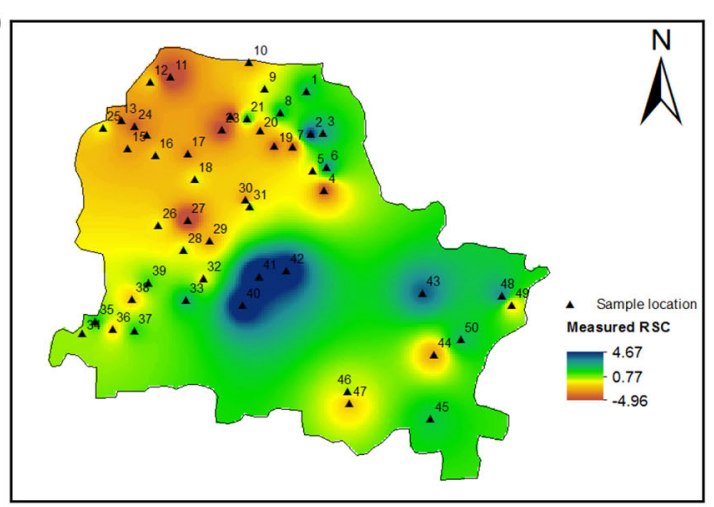

(c)

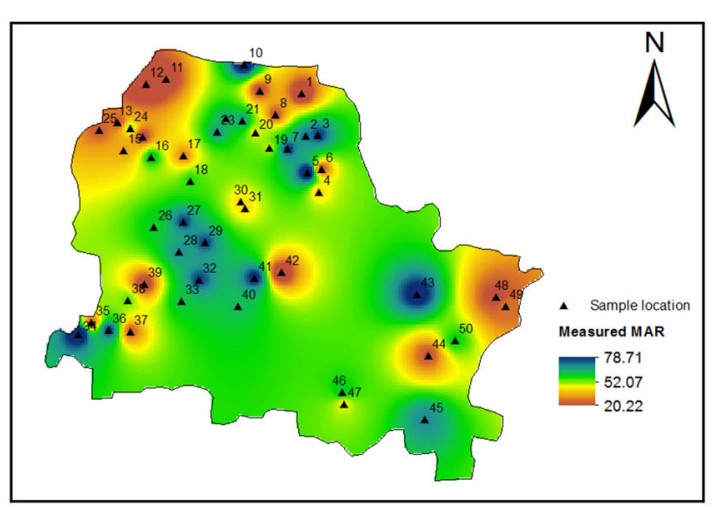

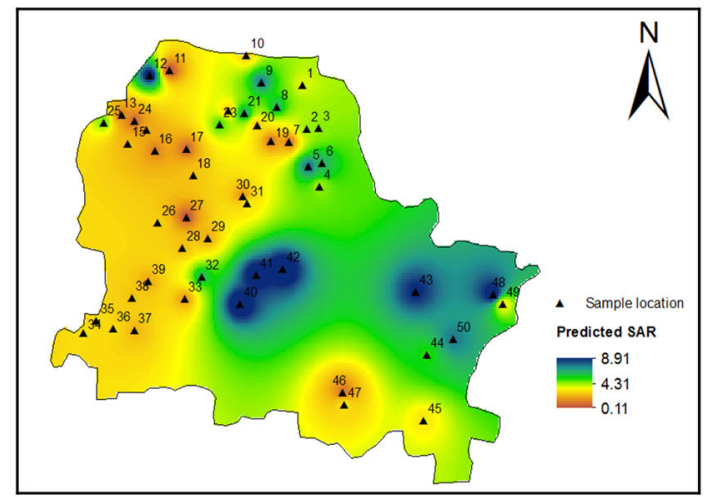
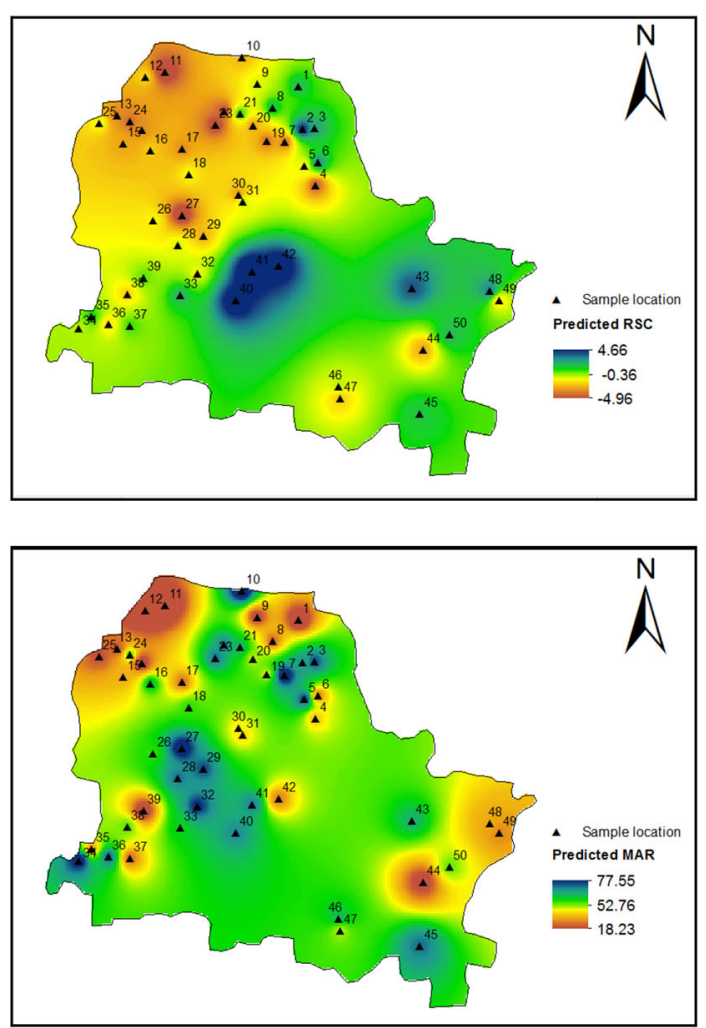

Fig. 4 Spatial distribution of measured and predicted ratio a SAR, b RSC, c MAR, d KR and e \% Na

\section{Conclusion}

The study demonstrated that, ANN provides vigorous tool for predicting SAR, RSC, MAR, KR and $\% \mathrm{Na}$ values in 50 observation wells of Nanded tehsil. A neural network model consisting 13 input neurons, 7 hidden neurons and 5 output variables were used for computing ground water suitability for irrigation in study area. The SAR, MAR and KR values increases due to excessive use of chemical fertilizers. The RSC and \% Na were found to be more precise as compared to SAR,
MAR, and KR values as per RMSE, $\mathrm{R}^{2}$ and MARE values of the predicted values. EC was most significant parameter within input parameters used in the modeling. The proposed model gave satisfactory fit to the experimentally obtained dataset in 50 observation wells. A comparison between different irrigation indices computed through ANN model and MS-Excel indicates that, it is capable of improving the accuracy to determine the suitability of ground water irrigation purpose. The spatial distribution map represents the accuracy of measured and predicted values. Hence, the proposed ANN model is 
(d)

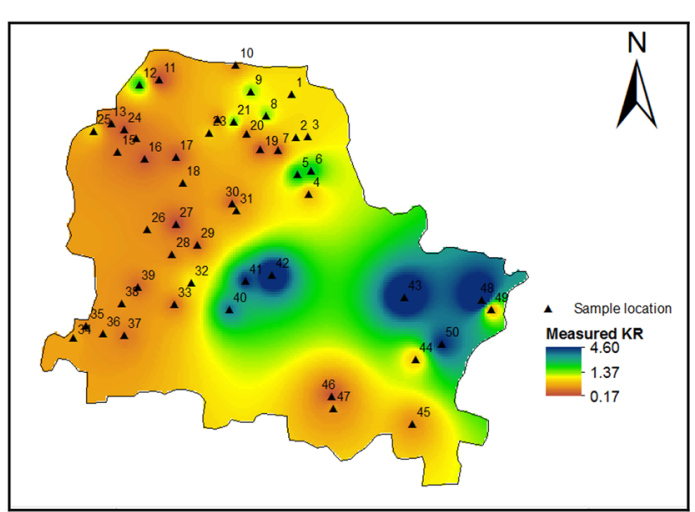

(e)

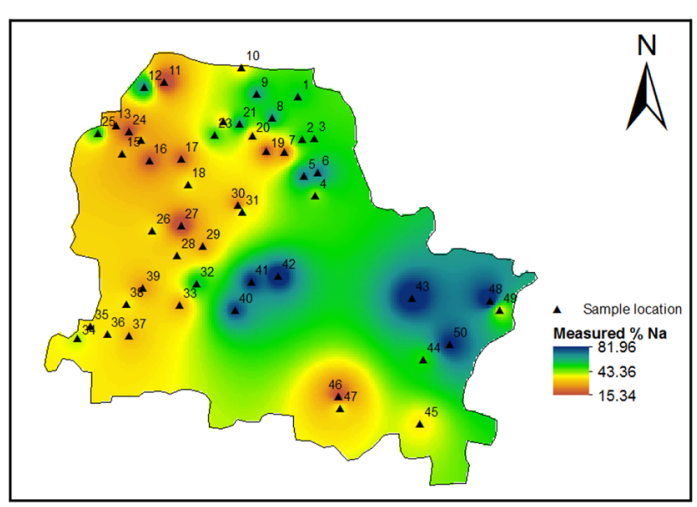

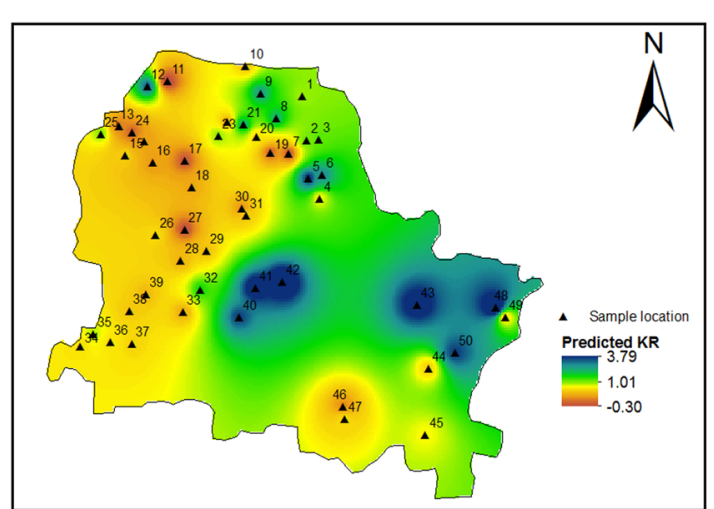

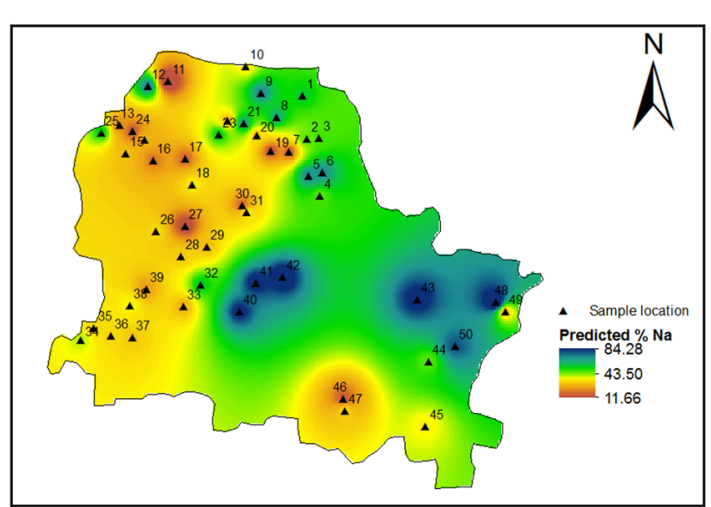

Fig. 4 continued

applicable to measure the ground water suitability for irrigation in easier way. This model can be considered by local development authorities for better management of groundwater resources.

Acknowledgements This research work was funded under minor research project scheme by Swami Ramanand Teerth Marathwada University, Nanded. The authors wish to thank The Director, School of Earth Sciences, for provided necessary facilities during the research work.

\section{References}

APHA (2005) Standard methods for the examination of water and wastewater, 21st edn. American Public Health Association, New York

Ayers RS, Westcot DW (1994) Water quality for agriculture. Rome: FAO. Irrigation and drainage paper, vol 29, p 174

Central Ground Water Board (CGWB) (2010) Groundwater quality in shallow aquifers of India. Ministry of Water Resources, Govt. of India, Nagpur, p 294

Central Ground Water Board (CGWB) (2013) Groundwater information Nanded district Maharashtra. Ministry of Water Resources, Govt. of India, Nagpur, p 294

Chang FJ, Tsai WP, Chen HK, Yam RSW, Herricks EE (2013) A selforganizing radial basis network for estimating riverine fish diversity. J Hydrol 476:280-289

Doneen LD (1964) Water quality for agriculture. Department of Irrigation, University of Calfornia, Calfornia
Eaton FM (1950) Significance of carbonates in irrigation waters. Soil Sci 69(2):123-134

Fijani E, Nadiri AA, Moghaddam AA, Tsai FTC, Dixon B (2013) Optimization of DRASTIC method by supervised committee machine artificial intelligence to assess groundwater vulnerability for Maragheh-Bonab plain aquifer, Iran. J Hydrol 503:89-100

Ghavidel SZZ, Montaseri M (2014) Application of different datadriven methods for the prediction of total dissolved solids in the Zarinehroud basin. Stoch Env Res Risk Assess 28(8):2101-2118

Goyal SK, Chaudhary BS, Singh O, Sethi GK, Thakur PK (2010) GIS based spatial distribution mapping and suitability evaluation of groundwater quality for domestic and agricultural purpose in Kaithal district, Haryana state, India. Environ Earth Sci 61(8):1587-1597

Jangam CM, Sanam SR, Chaturvedi MK, Padmakar C, Pujari PR, Labhasetwar PK (2015) Impact assessment of on-site sanitation system on groundwater quality in alluvial settings: a case study from Lucknow city in North India. Environ Monit Assess 187(10): $1-16$

Kelley WP (1963) Use of saline irrigation water. Soil Sci 95(6):385-391

Kirda C (1997) Assessment of irrigation water quality. Options Mediterraneennes. Serie A: Seminaires Mediterraneens (CIHEAM)

Kisi O, Tombul M, Kermani MZ (2015) Modeling soil temperatures at different depths by using three different neural computing techniques. Theoret Appl Climatol 121(1-2):377-387

Krishnan MS (1982) Geology of India and Burma, 6th edn. CBS Publisher and Distributors, New Delhi

Maqsood I, Khan MR, Huang GH, Abdalla R (2005) Application of soft computing models to hourly weather analysis in southern Saskatchewan, Canada. Eng Appl Artif Intell 18(1):115-125 
Nourani V, Baghanam AH, Adamowski J, Gebremichael M (2013) Using self-organizing maps and wavelet transforms for spacetime pre-processing of satellite precipitation and runoff data in neural network based rainfall-runoff modeling. J Hydrol 476:228-243

Raghunath HM (1987) Groundwater. Wiley Eastern Ltd, Delhi India

Richards Lorenzo Adolph (1954) Diagnosis and improvement of saline and alkali soils. Soil Sci 78(2):154

Rojas R (1996) A short proof of the posterior probability property of classifier neural networks. Neural Comput 8(1):41-43
Sreekanth PD, Geethanjali N, Sreedevi PD, Ahmed S, Kumar NR, Jayanthi PK (2009) Forecasting groundwater level using artificial neural networks. Curr Sci 96(7):933-939

Strik DP, Domnanovich AM, Zani L, Braun R, Holubar P (2005) Prediction of trace compounds in biogas from anaerobic digestion using the MATLAB neural network toolbox. Environ Model Softw 20(6):803-810 